\title{
Reduced ex vivo release of pro- inflammatory cytokines and elevated plasma interleukin- 6 are inflammatory signatures of post-stroke delirium
}

\author{
Katarzyna Kowalska', Elzbieta Klimiec ${ }^{1}$, Kazimierz Weglarczyk², Joanna Pera', Agnieszka Slowik', Maciej Siedlar² \\ and Tomasz Dziedzic ${ }^{1 *}$ (D)
}

\begin{abstract}
Background: Experimental studies suggest that systemic inflammation contributes to the pathophysiology of delirium. The aim of our study was to determine blood-derived inflammatory signatures of post-stroke delirium.

Methods: We included 144 ischemic stroke patients. We assessed delirium on a daily basis during the first 7 days of hospitalization. Venous blood was collected at day 3 after the onset of stroke and stimulated ex vivo with lipopolysaccharide (LPS). We measured LPS-induced cytokine concentration (TNFa, IP-10, IL-1 $\beta$, IL-6, IL-8, IL-10, and IL-12p70) as well as plasma levels of IL-6 and TNFa.

Results: Delirium was diagnosed in $21.5 \%$ of patients. After correction for monocyte count, patients with delirium had reduced LPS-induced TNFa, IP-10, IL-1 $\beta, I L-6$, and IL-12 release. The plasma IL-6 level was higher in delirious patients compared to patients without delirium. After adjusting for stroke severity and infections, higher ex vivo TNFa (OR 0.29, 95\%Cl 0.11-0.72, $P=0.01$ ), IP-10 (OR 0.25, 95\%Cl 0.08-0.73, $P=0.01)$, IL-1 $\beta$ (OR 0.42, 95\%Cl 0.20-0.89, $P=0.02)$, and IL-12 (OR $0.07,95 \% \mathrm{Cl} 0.01-0.70, P=0.02)$ release was associated with the reduced risk of delirium. In multivariate analysis, the higher plasma IL-6 was associated with the increased risk of delirium $(\mathrm{OR} 1.61,95 \% \mathrm{Cl}$ $1.00-2.58, P=0.04$ ).
\end{abstract}

Conclusions: Reduced ex vivo release of pro-inflammatory cytokines after LPS stimulation and the elevated plasma IL-6 are signatures of post-stroke delirium.

Keywords: Delirium, Cytokines, Stroke, Inflammation

\section{Background}

Delirium is a neuropsychiatric syndrome characterized by acute, fluctuating changes in attention, awareness, and cognition. Delirium is common among hospitalized elderly people and is associated with increased mortality and poor functional and cognitive outcome [1]. An estimated rate of delirium after stroke is $26 \%$ with a range of 10 to $48 \%$ [2].

The pathophysiology of delirium is still poorly understood. One of the current hypotheses of delirium suggests that acute peripheral inflammation induces activation of

\footnotetext{
*Correspondence: dziedzic@cm-uj.krakow.pl

'Department of Neurology, Jagiellonian University Medical College, ul. Botaniczna 3, 31-503 Krakow, Poland

Full list of author information is available at the end of the article
}

brain parenchymal cells and an expression of proinflammatory mediators in the brain. These neuroinflammatory changes evoke a synaptic and neuronal dysfunction and subsequent behavioral and cognitive symptoms [3-5]. The elderly and patients with neurodegenerative diseases are particularly prone to develop delirium triggered by systemic inflammation [3].

Although systemic inflammation is recognized as a trigger of delirium, there is still limited evidence that links circulating inflammatory mediators with delirium in humans. The most replicated finding, albeit not confirmed by some researchers, is the elevated blood interleukin (IL)- 6 level during delirium [6-9]. Other blood-based inflammatory mediators which predicted delirium or were elevated 
during delirium in some studies include $\mathrm{C}$-reactive protein (CRP) [10, 11], IL-1 [12], IL-2 [9, 13], IL-8 [7], tumor necrosis factor alpha (TNF $\alpha)[9,13]$, and soluble TNF $\alpha$ receptor 1 and $2[12,14]$.

Identification of blood-derived inflammatory signatures of delirium is important for better understanding interactions between the immune system and delirium and searching of potential biomarkers of delirium. In this study, we aimed to determine inflammatory signatures of post-stroke delirium. Toll-like receptor 4 (TLR4) is a master regulator of innate immunity. We assessed ex vivo cytokine release after whole blood stimulation with lipopolysaccharide (LPS) , an agonist of TLR4. For comparison, we measured plasma levels of two cytokines: IL-6 and TNF $\alpha$. We choose IL-6 because numerous studies demonstrated that the blood level of this cytokine is elevated in acute stroke patients and correlates with poor outcome [15]. Tumor necrosis factor alpha was chosen, because a few studies showed an associated between this cytokine and post-stroke infections [16].

\section{Methods}

\section{Patient selection and clinical assessment}

The participants for this study were prospectively recruited from stroke patients hospitalized in the Department of Neurology, University Hospital, Krakow, Poland, between October 2016 and June 2017. The inclusion criteria were as follows: (1) ischemic stroke, (2) time from the onset of stroke symptoms onset to admission $<24 \mathrm{~h}$, (3) pre-stroke modified Rankin Scale score 0-2 (independence in daily activities), (4) National Institute of Health Stroke Scale (NIHSS) score on admission $>3$, and (5) informed patient consent. The exclusion criteria were as follows: (1) chronic inflammatory, autoimmune or cancerous diseases; (2) coma; and (3) severe aphasia disabling the assessment of delirium's core features. Written informed consent was obtained from each patient included in the study. The study protocol conforms to the ethical guidelines of the 1975 Declaration of Helsinki. The study protocol was approved by the Bioethics Committee of Jagiellonian University.

Since the main goal of our study was to determine inflammatory signatures that are present during an episode of delirium, we excluded patients in whom delirium occurred before or after day 3 (i.e. the day of blood sampling), but who had no delirium's episode at day 3 .

The diagnosis of pneumonia required the presence of clinical findings (at least two from the following: productive cough and/or purulent sputum, rales, fever, and leukocytosis), as well as pulmonary infiltrates in chest Xray. Symptomatic urinary tract infection was diagnosed based on one of the following two sets of criteria: (1) at least one of the following signs is present: fever $\left(>38{ }^{\circ} \mathrm{C}\right)$, urgency, dysuria, or suprapubic tenderness and positive urine culture $\left(\geq 10^{5}\right.$ microorganisms per cubic centimetre with no more than two species of microorganisms), or (2) at least one of the following signs is present: fever $\left(>38^{\circ} \mathrm{C}\right)$, urgency, dysuria, or suprapubic tenderness and at least two of the following: positive dipstick for leukocyte esterase and/or nitrate, pyuria (urine specimen with $\geq 10$ white blood cell $/ \mathrm{mm}^{3}$ ), and organisms seen in Gram stains of unspun urine [17].

Patients were screened for delirium on daily basis during first 7 days after admission. Core features of delirium were assessed using Brief Confusion Assessment Method (bCAM) for verbal patients [18] and Intensive Care Units version (CAM-ICU) for non-verbal patients [19]. The final diagnosis of delirium was based on DMS-5 criteria [20].

The Informant Questionnaire on Cognitive Decline in the Elderly (IQCODE) was used to diagnose a pre-stroke cognitive decline [21]. IQCODE consists of 26 items that rate the change in patients' intellectual abilities over the past 10 years. A cutoff of 3.3 was chosen to diagnose a pre-stroke cognitive decline [22].

No formal protocol was used to treat delirium. In general, management of delirium included early mobilization, treatment of infections and pain, control of fluids and electrolytes, and use of visual and hearing aids in patients with sensory impairment. Neuroleptics were given only to patients with severe agitation.

\section{Laboratory assays}

To avoid diurnal variation in cytokine production, blood was obtained at day 3 after stroke rather than upon admission. Venous blood was collected in heparinized tubes (Sarstedt, Germany) between 7:00 AM and 7:30 AM. The whole blood was diluted by 1:5 in sterile RPMI 1640 medium supplemented with L-glutamine (Sigma Aldrich, St. Louis, MO) and stimulated for $4 \mathrm{~h}$ at $37^{\circ} \mathrm{C}$ and $5 \% \mathrm{CO}_{2}$ with LPS (10 ng/mL, E. coli 0111:B4, Sigma Aldrich, St. Louis, MO) in sterile tubes (Lonza, Walkersville, MD). The supernatants were removed and stored at $-80{ }^{\circ} \mathrm{C}$ until further analysis.

Similar to some previous studies [17, 23, 24], LPSinduced cytokines were normalized for monocyte count, because monocytes are the main producers of cytokines after whole blood stimulation with endotoxin [25]. Moreover, normalization by monocyte count reduced the coefficient of variation [26]. Taking into account the previous publications $[17,23,27]$ and our own preliminary experiments on kinetics of cytokine release after whole blood stimulation, a stimulation was performed for $4 \mathrm{~h}$ for TNF $\alpha$ and interferon-gamma-inducible protein 10 (IP-10) and $24 \mathrm{~h}$ for interleukin(IL)-1 $\beta$, IL-6, IL-8, IL-10, and IL12p70. TNF $\alpha$ and IP-10 concentration was measured using commercially available ELISA kits from R\&D Systems (Minneapolis, MN). Concentration of IL-1 $\beta$, IL-6, IL-8, IL-10, and IL-12p70 was determined by a cytometric bead array immunoassay (Human Inflammatory Kit, BD Bioscience, San Diego, CA). 
Plasma level of TNF $\alpha$ and IL- 6 was measured using ELISA kits from R\&D Systems (Minneapolis, MN). Cytokine detection limits were $0.19 \mathrm{pg} / \mathrm{mL}$ for $\mathrm{TNF} \alpha$ and $0.11 \mathrm{pg} / \mathrm{mL}$ for IL-6.

\section{Statistical analysis}

The $X^{2}$ test was used to compare proportions, while the Mann-Whitney $U$ test was used to compare continuous variables between groups. Logistic regression was used to determine the predictors of functional outcome. Distribution of cytokines was standardized to a mean 0 and standard deviation of 1 . NIHSS score on admission were put to a model as continuous variables. Variables with $P<0.05$ in univariate analysis were included in multivariate analysis. The Box-Tidwell test was used to check the linearity of the logit for the continuous independent variables in logistic regression analysis. The calculations were performed using the program STATISTICA for Windows (version 12.5, Statsoft, Poland). The calculated odds ratios are per standard deviation.

In additional analysis, we assessed an association between raw values of LPS-induced cytokine (not normalized for monocyte count) and delirium. We used the receiver operating characteristic curves to find an optimal cutoff level of cytokines that differentiates delirious patients from non-delirious patients.

\section{Results}

We recruited 157 stroke patients. From final analysis, we excluded patients who had no delirium at day 3 (i.e. the day of blood collection), but who developed delirium before $(N=10)$ or after day $3(N=3)$.

The final cohort included 144 patients (median age 69, IQs 63-79; 57.6\% male). Delirium was diagnosed in 21. $5 \%$ of patients. Baseline characteristics of the patients with delirium and the patients without delirium are shown in Table 1.

Patients with delirium had more severe neurological deficit on admission and more often suffered from pneumonia and urinary tract infection.

Compared to patients without delirium, delirious patients exhibited reduced release of TNF $\alpha$, IP-10, IL$1 \beta$, IL-6, and IL-12 after whole blood stimulation with LPS (Table 2). The plasma level of IL-6, but not TNF $\alpha$, was higher in patients with delirium.

The results of univariate analysis and multivariate analysis are shown in Table 3.

In univariate analysis, higher release of TNF $\alpha$ (OR 0. 19, 95\%CI 0.09-0.41, $P<0.01$ ), IP-10 (OR 0.13, 95\%CI 0. 04-0.38, $P<0.01$ ), IL-1 $\beta$ (OR 0.34, 95\%CI 0.18-0.67, $P<$ 0.01 ), IL-6 (OR 0.62, 95\%CI 0.40-0.96, $P=0.03$ ), and IL12 (OR $0.06,95 \%$ CI $0.01-0.48, P=0.01$ ) was associated with the reduced risk of delirium. Higher plasma IL-6 level was associated with the increased risk of delirium (OR 2.77, 95\%CI 1.53-5.04, $P<0.01$ ).

An association between delirium and reduced release of TNF $\alpha$ (OR 0.29 , 95\%CI $0.11-0.72, P=0.01$ ), IP-10 (OR 0.25, 95\%CI 0.08-0.73, $P=0.01$ ), IL-1 $\beta$ (OR 0.42, 95\%CI $0.20-0.89, P=0.02$ ), and IL-12 (OR 0.07, 95\%CI $0.01-0.70, P=0.02)$ as well as the increased plasma IL-6 (OR 1.61, 95\%CI 1.00-2.58, $P=0.04$ ) remained

Table 1 Characteristics of patients with delirium and patients without delirium

\begin{tabular}{|c|c|c|c|}
\hline & Patients with delirium $(N=31)$ & Patients without delirium $(N=113)$ & $P$ value \\
\hline Age, median (IQs) & $71(64-80)$ & $68(63-79)$ & 0.57 \\
\hline Male, $n(\%)$ & $18(58.1)$ & $65(57.5)$ & 0.96 \\
\hline Hypertension, $n$ (\%) & $24(77.4)$ & $82(72.6)$ & 0.59 \\
\hline Diabetes mellitus, $n(\%)$ & $8(25.8)$ & $30(26.5)$ & 0.93 \\
\hline Atrial fibrillation, $n(\%)$ & $13(41.9)$ & $32(28.3)$ & 0.15 \\
\hline Myocardial infarction, $n(\%)$ & $5(16.1)$ & $14(12.4)$ & 0.58 \\
\hline Previous stroke, $n(\%)$ & $3(9.7)$ & $14(12.4)$ & 0.68 \\
\hline IQCODE $>3.3, n(\%)^{\mathrm{a}}$ & $3 / 24(12.5)$ & 9/85 (10.6) & 0.79 \\
\hline NIHSS score on admission, median (IQs) & $17(15-20)$ & $7(5-15)$ & $<0.01$ \\
\hline Pneumonia, $n(\%)$ & $9(29.0)$ & $3(2.6)$ & $<0.01$ \\
\hline Urinary tract infection, $n(\%)^{b}$ & $13 / 30(43.3)$ & 20/99 (20.2) & 0.01 \\
\hline White blood cells count, $\times 10^{3} / \mu \mathrm{L}$, median (IQs) & $11.7(9.3-12.9)$ & $8.3(6.6-9.6)$ & $<0.01$ \\
\hline Monocyte count, $\times 10^{3} / \mu \mathrm{L}$, median (IQs) & $1.1(0.9-1.2)$ & $0.8(0.6-1.0)$ & $<0.01$ \\
\hline Intravenous thrombolysis, n (\%) & $20(64.5)$ & $64(56.6)$ & 0.43 \\
\hline Mechanical thrombectomy, $n$ (\%) & $7(22.6)$ & $24(21.2)$ & 0.87 \\
\hline
\end{tabular}

IQs interquartiles, IQCODE the Informant Questionnaire on Cognitive Decline in the Elderly

${ }^{a}$ Data available for 109 patients

${ }^{\mathrm{b}}$ Data available for 129 patients 
Table 2 Cytokine levels in patients with delirium and patients without delirium

\begin{tabular}{|c|c|c|c|}
\hline & Patients with delirium $(N=31)$ & Patients without delirium $(N=113)$ & $P$ value \\
\hline \multicolumn{4}{|l|}{ Ex vivo stimulation } \\
\hline TNFa, pg/103 monocytes & $1.76(1.47-2.32)$ & $3.17(2.31-4.42)$ & $<0.01$ \\
\hline IP-10, pg/10 $10^{3}$ monocytes & $0.17(0.10-0.46)$ & $0.56(0.32-0.92)$ & $<0.01$ \\
\hline IL-1 $\beta$, pg/10 $30^{3}$ monocytes & $1.12(0.62-1.78)$ & $1.85(1.26-2.61)$ & $<0.01$ \\
\hline IL-6, pg/10 $10^{3}$ monocytes & $10.37(8.55-14.52)$ & $14.21(9.81-18.16)$ & 0.02 \\
\hline IL-12, pg/10 monocytes & $0(0-0)$ & $1.46(0-8.57)$ & $<0.01$ \\
\hline IL-10, pg/10 monocytes & $66.58(39.57-86.54)$ & $59.70(36.85-99.02)$ & 0.82 \\
\hline IL-8, pg/10 $10^{3}$ monocytes & $2.03(1.51-2.93)$ & $1.64(1.08-2.56)$ & 0.13 \\
\hline TNFa, pg/mL & 2066 (1578-2550) & $2404(1555-3869)$ & 0.03 \\
\hline $\mathrm{IP}-10, \mathrm{pg} / \mathrm{mL}$ & $166.97(108.45-366.40)$ & $436.10(201.28-797.10)$ & $<0.01$ \\
\hline $\mathrm{IL}-1 \beta, \mathrm{pg} / \mathrm{mL}$ & $1153(680-1690)$ & 1325 (1046-2092) & 0.11 \\
\hline IL-6, pg/mL & $10,455(8885-16,362)$ & $10,407(7280-13,319)$ & 0.41 \\
\hline $\mathrm{IL}-12, \mathrm{pg} / \mathrm{mL}$ & $0(0-0)$ & $1.48(0-6.91)$ & $<0.01$ \\
\hline $\mathrm{IL}-10, \mathrm{pg} / \mathrm{mL}$ & $69.23(36.67-103.38)$ & $46.62(31.99-72.11)$ & 0.06 \\
\hline IL-8, pg/mL & 2240 (1469-3209) & $1279(872-2055)$ & $<0.01$ \\
\hline \multicolumn{4}{|l|}{ Plasma } \\
\hline TNFa, pg/ml & $0.91(0.53-1.27)$ & $0.70(0.36-1.12)$ & 0.09 \\
\hline IL-6, pg/mL & 17.95 (7.09-46.75) & $3.94(2.21-7.29)$ & $<0.01$ \\
\hline
\end{tabular}

Data are shown as medians with interquartiles

significant after adjusting for stroke severity (NIHSS score on admission), pneumonia, and urinary tract infection.

Finally, we analysed an association between delirium and raw values of LPS-induced cytokine (not normalized for monocyte count). Delirious patients had reduced release of TNF $\alpha$, IP-10, and IL-12 and increased release of IL- 8 compared to patients without delirium (Table 2). In univariate analysis, TNF $\alpha<2857.6 \mathrm{pg} / \mathrm{mL}$ (OR 7.86, 95\%CI 2.27-27.22, $P<0.01$ ), IP-10<333.4 pg/mL (OR 4.30, 95\%CI 1.99-9.28, $P<0.01$ ), IL-12 $<0.30 \mathrm{pg} / \mathrm{mL}$
(OR 2.78, 95\%CI 1.35-5.72, $P<0.01$ ), IL-10 $>57.0 \mathrm{pg} / \mathrm{mL}$ (OR 2.52, 95\%CI 1.23-5.16, $P=0.01$ ), and IL-8 $>1786.4 \mathrm{pg} /$ $\mathrm{mL}$ (OR 5.00, 95\%CI 2.36-10.60, $P<0.01$ ) were associated with delirium. An association between delirium and TNF $\alpha$ $<2857.6 \mathrm{pg} / \mathrm{mL}$ (OR 6.14, 95\%CI 1.52-24.73 $P=0.01$ ), IP$10<333.4 \mathrm{pg} / \mathrm{mL}$ (OR 2.61, 95\%CI 1.04-6.55, $P=0.04)$, IL$10>57.0 \mathrm{pg} / \mathrm{mL}$ (OR 3.72, 95\%CI 1.46-9.47, $P=0.01)$, and IL-8 $>1786.4 \mathrm{pg} / \mathrm{mL}$ (OR 5.18, 95\%CI 2.08-12.93, $P<0.01$ ) remained significant after adjusting for NIHSS score, pneumonia, and urinary tract infection.

Table 3 Results of uni- and multivariate analysis

\begin{tabular}{|c|c|c|}
\hline & Univariate analysis & Multivariate analysis $^{a}$ \\
\hline \multicolumn{3}{|c|}{ Ex vivo stimulation } \\
\hline TNFa & OR $0.19,95 \% C l 0.09-0.41, P<0.01$ & OR $0.29,95 \% \mathrm{Cl} 0.11-0.72, \mathrm{P}=0.01$ \\
\hline IP-10 & OR $0.13,95 \% \mathrm{Cl} 0.04-0.38, \mathrm{P}<0.01$ & OR $0.25,95 \% \mathrm{Cl} 0.08-0.73, P=0.01$ \\
\hline $\mathrm{IL}-1 \beta$ & OR $0.34,95 \% C l$ l $0.18-0.67, P<0.01$ & OR $0.42,95 \% \mathrm{Cl} 0.20-0.89, \mathrm{P}=0.02$ \\
\hline IL-6 & OR $0.62,95 \% \mathrm{Cl} 0.40-0.96, P=0.03$ & OR $0.76,95 \% \mathrm{Cl} 0.43-1.35, \mathrm{P}=0.35$ \\
\hline $\mid \mathrm{L}-12$ & OR $0.06,95 \% \mathrm{Cl} 0.01-0.48, P=0.01$ & OR $0.07,95 \% \mathrm{Cl} 0.01-0.70, P=0.02$ \\
\hline IL-10 & OR $0.85,95 \% \mathrm{Cl} 0.55-1.30, P=0.44$ & OR $1.00,95 \% \mathrm{Cl} 0.59-1.69, \mathrm{P}=0.99$ \\
\hline IL-8 & OR $1.15,95 \% \mathrm{Cl} 0.80-1.66, P=0.43$ & OR $1.34,95 \% \mathrm{Cl} 0.80-2.24, \mathrm{P}=0.26$ \\
\hline \multicolumn{3}{|l|}{ Plasma } \\
\hline TNFa & OR $1.16,95 \% \mathrm{Cl} 0.81-1.68, P=0.41$ & OR $0.89,95 \% \mathrm{Cl} 0.53-1.48, \mathrm{P}=0.64$ \\
\hline IL-6 & OR 2.77, 95\%Cl 1.53-5.04, $P<0.01$ & OR $1.61,95 \% \mathrm{Cl} 1.00-2.58, \mathrm{P}=0.04$ \\
\hline
\end{tabular}

${ }^{a}$ Adjusted for NIHSS score on admission, pneumonia, and urinary tract infection ORs are per standard deviation 


\section{Discussion}

We found reduced release of TNF $\alpha$, IP-10, IL-1 $\beta$, and IL-12 after ex vivo blood stimulation and the elevated plasma IL-6 level in delirious patients.

To our best knowledge, it is the first report showing diminished ex vivo release of pro-inflammatory cytokines in patients with delirium. This finding is consistent with transient post-stroke immunodepression [28]. In acute stroke patients, circulating monocytes exhibit an endotoxin tolerance status that manifests as the reduced TNF $\alpha$ synthesis and the diminished HLA-DR expression after LPS challenge [29]. An endotoxin tolerant state is a phenomenon observed in patients with different pathologies including sepsis, acute coronary syndrome, heart failure, and cancer [30]. Endotoxin tolerance is a key mechanism to limit an excessive innate reaction to infection or injury. It was suggested that post-stroke immunodepression is triggered by over-activation of the sympathetic nervous system and the release of damageassociated molecular patterns (DAMPs) $[29,31]$. It would be interesting to examine in future studies a relationship between markers of autonomic nervous systems, circulating DAMPs and delirium.

Other mechanism which could be responsible for poststroke immunodepression is a release of high mobility group box 1 (HMGB1) from the necrotic brain tissue to blood. In vitro, extracellular HMGB1 induced endotoxin tolerance in macrophages [32]. In the animal model of cerebral ischemia, circulating HMGB1 acting via the receptor of advanced glycation end-products (RAGE) was responsible for the reduced secretion of TNF $\alpha$ and IL-12 by monocytes and lymphopenia [33]. A relationship between delirium and circulating HMGB1 requires further investigation.

We confirmed and extended previous studies examining an association between IL- 6 and delirium. IL- 6 is the strongest activator of the hepatic acute phase reaction, and its blood levels are elevated in many infectious and inflammatory diseases [34]. Higher blood levels of IL-6 were observed among delirious patients after cardiac surgery [8], hip fracture [7], and major elective surgery [9] as well as older patients acutely admitted to the hospital [6]. In stroke patients, a source of circulating IL-6 seems to be an ischemic brain or an adipose tissue [35].

In our study, plasma TNF $\alpha$ level did not differ significantly between patients with delirium and patients without delirium. The studies examining an association between this cytokine and delirium yielded conflicting results. A few studies reported the elevated level of circulating TNF $\alpha$ in patients with post-operative delirium $[9,13]$ whereas other studies did not find such as an association [7, 36].

The additional analysis of an association between values of LPS-induced cytokine not normalized for monocyte count and delirium revealed increased release of IL- 8 and
IL-10 in delirious patients. Increased production of IL-10, the prototypic anti-inflammatory cytokine, in delirious patients supports an idea that post-stroke immunodepression is linked to delirium. Increased release of IL-8 after blood stimulation with endotoxin is consistent with the observation of elevated serum levels of IL-8 in elderly patients with delirium after hip fracture [7].

Taking together, post-stroke delirium was associated with both immunodepression and systemic inflammation reflected by elevated circulating IL-6.

Our study has several limitations. Our results relied on only single cytokine measurement. It remains unclear if resolution of delirium is associated with any change in cytokine synthesis. In this kind of study, pre-stroke ex vivo cytokine synthesis and circulating cytokine level could not be assessed. We cannot exclude a possibility that some of our patients could have delirium only in the first hours of stroke before admission. Our findings could not be generalized on non-stroke patients with delirium and require confirmation in different groups of delirious patients.

\section{Conclusion}

In conclusion, reduced ex vivo release of pro-inflammatory cytokines after LPS stimulation and elevated plasma IL-6 are signatures of post-stroke delirium.

\section{Funding}

This study was supported by the grant from the National Science Center (2015/19/B/NZ4/00287)

\section{Availability of data and materials}

The datasets used during the current study are available from the corresponding author on reasonable request.

\section{Authors' contributions}

KT prepared the study protocol; collected, analyzed, and interpreted the data; and prepared the manuscript. EK and JP collected and interpreted the data. KW performed the cytometric assay and analyzed the data. AS and MS revised the manuscript for intellectual content. TD prepared the study protocol; analyzed and interpreted the data; supervised the study; and prepared the manuscript. All authors read and approved the final manuscript.

\section{Ethics approval and consent to participate}

Written informed consent was obtained from each patient included in the study. The study protocol was approved by the Bioethics Committee of Jagiellonian University (opinion number: 122.6120.249.2016).

\section{Competing interests}

The authors declare that they have no competing interests.

\section{Publisher's Note}

Springer Nature remains neutral with regard to jurisdictional claims in published maps and institutional affiliations.

\section{Author details}

'Department of Neurology, Jagiellonian University Medical College, ul. Botaniczna 3, 31-503 Krakow, Poland. ²Department of Clinical Immunology, Institute of Paediatrics, Jagiellonian University Medical College, Krakow, Poland. 
Received: 6 February 2018 Accepted: 9 April 2018 Published online: 18 April 2018

\section{References}

1. Inouye SK, Westendorp RG, Saczynski JS. Delirium in elderly people. Lancet. 2014;383:911-22.

2. Klimiec E, Dziedzic T, Kowalska K, Slowik A, Klimkowicz-Mrowiec A. Knowns and unknowns about delirium in stroke: a review. Cogn Behav Neurol. 2016:29:174-89.

3. Cerejeira J, Firmino H, Vaz-Serra A, Mukaetova-Ladinska EB. The neuroinflammatory hypothesis of delirium. Acta Neuropathol. 2010:119:737-54.

4. Maldonado JR. Neuropathogenesis of delirium: review of current etiologic theories and common pathways. Am J Geriatr Psychiatry. 2013;21:1190-222.

5. Cunningham C, Maclullich AM. At the extreme end of the psychoneuroimmunological spectrum: delirium as a maladaptive sickness behaviour response. Brain Behav Immun. 2013;28:1-13.

6. de Rooij SE, van Munster BC, Korevaar JC, Levi M. Cytokines and acute phase response in delirium. J Psychosom Res. 2007:62:521-5.

7. van Munster BC, Korevaar JC, Zwinderman AH, Levi M, Wiersinga WJ, De Rooij SE. Time-course of cytokines during delirium in elderly patients with hip fractures. J Am Geriatr Soc. 2008;56:1704-9.

8. Plaschke K, Fichtenkamm P, Schramm C, Hauth S, Martin E, Verch M, Karck $M$, Kopitz J. Early postoperative delirium after open-heart cardiac surgery is associated with decreased bispectral EEG and increased cortisol and interleukin-6. Intensive Care Med. 2010;36:2081-9.

9. Vasunilashorn SM, Ngo L, Inouye SK, Libermann TA, Jones RN, Alsop DC, Guess J, Jastrzebski S, McElhaney JE, Kuchel GA, Marcantonio ER. Cytokines and postoperative delirium in older patients undergoing major elective surgery. J Gerontol A Biol Sci Med Sci. 2015;70:1289-95.

10. Dillon ST, Vasunilashorn SM, Ngo L, Otu HH, Inouye SK, Jones RN, Alsop DC, Kuchel GA, Metzger ED, Arnold SE, Marcantonio ER, Libermann TA. Higher C-reactive protein levels predict postoperative delirium in older patients undergoing major elective surgery: a longitudinal nested case-control study. Biol Psychiatry. 2017:81:145-53.

11. Vasunilashorn SM, Dillon ST, Inouye SK, Ngo LH, Fong TG, Jones RN, Travison TG, Schmitt EM, Alsop DC, Freedman SD, Arnold SE, Metzger ED, Libermann TA, Marcantonio ER. High C-reactive protein predicts delirium incidence, duration, and feature severity after major noncardiac surgery. J Am Geriatr Soc. 2017:65:e109-16.

12. Ritter C, Tomasi CD, Dal-Pizzol F, Pinto BB, Dyson A, de Miranda AS, Comim CM, Soares M, Teixeira AL, Quevedo J, Singer M. Inflammation biomarkers and delirium in critically ill patients. Crit Care. 2014;18:R106.

13. Kazmierski J, Banys A, Latek J, Bourke J, Jaszewski R. Raised IL-2 and TNF-a concentrations are associated with postoperative delirium in patients undergoing coronary-artery bypass graft surgery. Int Psychogeriatr. 2014;26:845-55.

14. Girard TD, Ware LB, Bernard GR, Pandharipande PP, Thompson JL, Shintani AK, Jackson JC, Dittus RS, Ely EW. Associations of markers of inflammation and coagulation with delirium during critical illness. Intensive Care Med. 2012;38:1965-73.

15. Dziedzic T. Clinical significance of acute phase reaction in stroke patients. Front Biosci. 2008;13:2922-7.

16. Dziedzic T. Systemic inflammation as a therapeutic target in acute ischemic stroke. Expert Rev Neurother. 2015;15:523-31.

17. Klimiec E, Kowalska K, Pasinska P, Pera J, Slowik A, Dziedzic T. Reduced release of TNFa and IP-10 after ex vivo blood stimulation with endotoxin is associated with poor outcome after stroke. Cytokine. 2018;10:51-4.

18. Han JH, Wilson A, Vasilevskis EE, Shintani A, Schnelle JF, Dittus RS, Graves AJ, Storrow AB, Shuster J, Ely EW. Diagnosing delirium in older emergency department patients: validity and reliability of the delirium triage screen and the brief confusion assessment method. Ann Emerg Med. 2013;62:457-65.

19. Ely EW, Inouye SK, Bernard GR, Gordon S, Francis J, May L, Truman B, Speroff T, Gautam S, Margolin R, Hart RP, Dittus R. Delirium in mechanically ventilated patients: validity and reliability of the confusion assessment method for the intensive care unit (CAM-ICU). JAMA. 2001;286:2703-10.

20. American Psychiatric Association. Diagnostic and statistical manual of mental disorders. 5th ed. Arlington: APA; 2013

21. Jorm AF, Korten AE. Assessment of cognitive decline in the elderly by informant interview. Br J Psychiatry. 1988;152:209-13.
22. Harrison JK, Fearon P, Noel-Storr AH, McShane R, Stott DJ, Quinn TJ. Informant Questionnaire on Cognitive Decline in the Elderly (IQCODE) for the diagnosis of dementia within a secondary care setting. Cochrane Database Syst Rev. 2015;3:CD010772.

23. Ertel W, Kremer JP, Kenney J, Steckholzer U, Jarrar D, Trentz O, Schildberg FW. Downregulation of proinflammatory cytokine release in whole blood from septic patients. Blood. 1995;85:1341-7.

24. Kox M, de Kleijn S, Pompe JC, Ramakers BP, Netea MG, van der Hoeven JG, Hoedemaekers CW, Pickkers P. Differential ex vivo and in vivo endotoxin tolerance kinetics following human endotoxemia. Crit Care Med. 2011;39:1866-70.

25. Damsgaard CT, Lauritzen L, Calder PC, Kjaer TM, Frøkiaer H. Whole-blood culture is a valid low-cost method to measure monocytic cytokines-a comparison of cytokine production in cultures of human whole-blood, mononuclear cells and monocytes. J Immunol Methods. 2009;340:95-101.

26. Segre E, Fullerton JN. Stimulated whole blood cytokine release as a biomarker of immunosuppression in the critically ill: the need for a standardized methodology. Shock. 2016;45:490-4.

27. van der Linden MW, Huizinga TW, Stoeken DJ, Sturk A, Westendorp RG. Determination of tumour necrosis factor-alpha and interleukin-10 production in a whole blood stimulation system: assessment of laboratory error and individual variation. J Immunol Methods. 1998:218:63-71.

28. Dirnagl U, Klehmet J, Braun JS, Harms H, Meisel C, Ziemssen T, Prass K, Meisel A. Stroke-induced immunodepression: experimental evidence and clinical relevance. Stroke. 2007;38(2 Suppl):770-3.

29. Hernández-Jiménez E, Gutierrez-Fernández M, Cubillos-Zapata C, OteroOrtega L, Rodríguez-Frutos B, Toledano V, Martínez-Sánchez P, Fuentes B, Varela-Serrano A, Avendaño-Ortiz J, Blázquez A, Mangas-Guijarro MÁ, DíezTejedor E, López-Collazo E. Circulating monocytes exhibit an endotoxin tolerance status after acute ischemic stroke: mitochondrial DNA as a putative explanation for poststroke infections. J Immunol. 2017;198:2038-46.

30. López-Collazo E, del Fresno C. Pathophysiology of endotoxin tolerance: mechanisms and clinical consequences. Crit Care. 2013:17:242.

31. Prass K, Meisel C, Höflich C, Braun J, Halle E, Wolf T, Ruscher K, Victorov IV, Priller J, Dirnagl U, Volk HD, Meisel A. Stroke-induced immunodeficiency promotes spontaneous bacterial infections and is mediated by sympathetic activation reversal by poststroke $T$ helper cell type 1 -like immunostimulation. J Exp Med. 2003;198:725-36.

32. Aneja RK, Tsung A, Sjodin H, Gefter JV, Delude RL, Billiar TR, Fink MP. Preconditioning with high mobility group box 1 (HMGB1) induces lipopolysaccharide (LPS) tolerance. J Leukoc Biol. 2008;84:1326-34.

33. Liesz A, Dalpke A, Mracsko E, Antoine DJ, Roth S, Zhou W, Yang H, Na SY, Akhisaroglu M, Fleming T, Eigenbrod T, Nawroth PP, Tracey KJ, Veltkamp R. DAMP signaling is a key pathway inducing immune modulation after brain injury. J Neurosci. 2015;35:583-98.

34. Schaper F, Rose-John S. Interleukin-6: biology, signaling and strategies of blockade. Cytokine Growth Factor Rev. 2015;26:475-87.

35. Shin JA, Jeong SI, Kim M, Yoon JC, Kim HS, Park EM. Visceral adipose tissue inflammation is associated with age-related brain changes and ischemic brain damage in aged mice. Brain Behav Immun. 2015;50:221-31.

36. Rudolph JL, Ramlawi B, Kuchel GA, McElhaney JE, Xie D, Sellke FW, Khabbaz K, Levkoff SE, Marcantonio ER. Chemokines are associated with delirium after cardiac surgery. J Gerontol A Biol Sci Med Sci. 2008;63:184-9.

\section{Ready to submit your research? Choose BMC and benefit from:}

- fast, convenient online submission

- thorough peer review by experienced researchers in your field

- rapid publication on acceptance

- support for research data, including large and complex data types

- gold Open Access which fosters wider collaboration and increased citations

- maximum visibility for your research: over $100 \mathrm{M}$ website views per year

At BMC, research is always in progress.

Learn more biomedcentral.com/submissions 